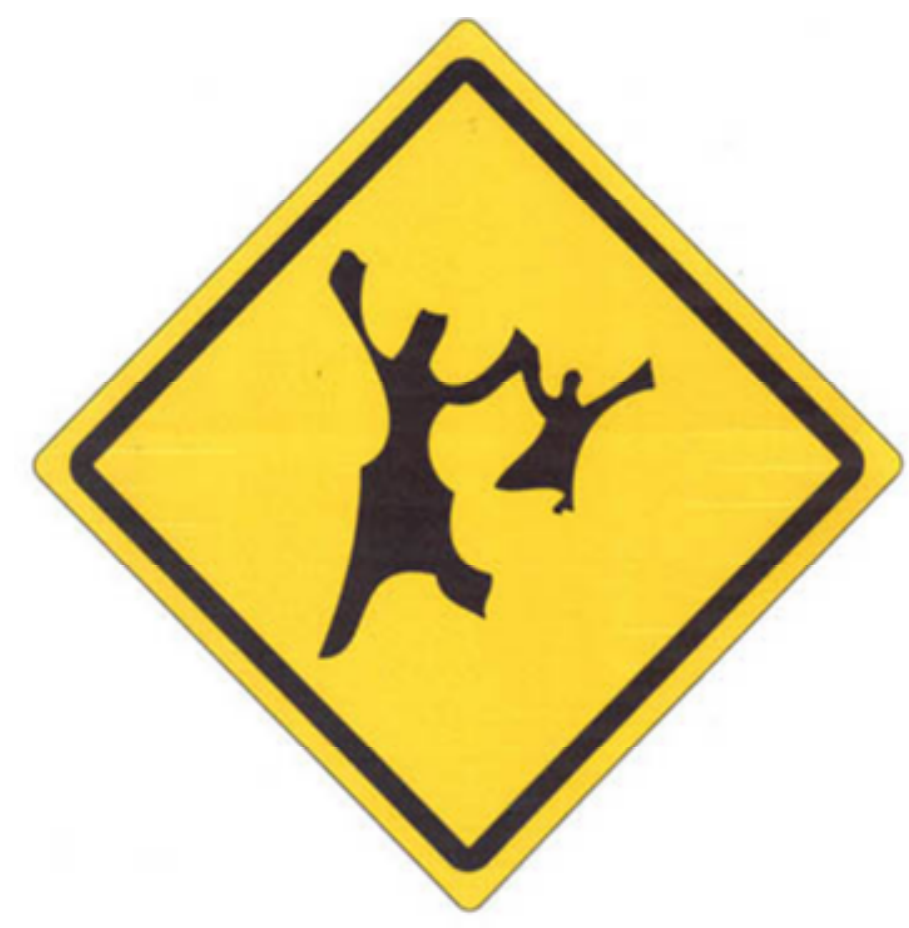

\title{
Estratégias de formação do hábito de leitura
}

\section{Juliana Xavier de Castro}

Graduanda em Letras/UFMG. Em 2006, concluiu pesquisa de Iniciação Científica e, em 2007, desenvolve uma nova pesquisa (bolsa Probic). Subcoordenadora da Página Eletrônica e monitora do Setor de Cursos e Oficinas do Programa A tela e o texto.

\section{Resumo}

Este trabalho teve como objetivo observar e analisar as estratégias de formação do hábito de leitura dos participantes de duas oficinas de letramento e inclusão digital realizadas, respectivamente, pelo Programa de Ensino, Pesquisa e Extensão A tela e o texto (FALE/UFMG) e pelo Programa de Educação de Jovens e Adultos (EJA), em Belo Horizonte. A partir da observação das oficinas e da análise dos dados à luz de bibliografia específica, verificou-se que a formação de leitores não contempla satisfatoriamente o uso de bibliotecas 
da região, mas explora os recursos de multimídia (TV, vídeo e computador) o que denota, na atualidade, uma profunda mudança na recepção de textos literários.

Palavras-chave: formação de leitores, mídia, recepção de textos.

\section{Formação de leitores}

Esta pesquisa teve como objetivo observar e analisar as estratégias de formação do hábito de leitura a partir de duas turmas, situadas em projetos diferentes. Um desses trabalhos foi desenvolvido sob a forma de uma oficina localizada na região do Barreiro. Essa oficina teve como objetivos despertar - interesse pela leitura de diversos textos como o literário, além de proporcionar a inclusão digital e o letramento dos participantes. O outro projeto foi desenvolvido numa turma da Educação de Jovens e Adultos, organizada pela Escola Sindical 7 de Outubro, na Escola Municipal União Comunitária em parceria com sindicatos, UFMG e Prefeitura de Belo Horizonte.

A partir dessas duas turmas, observei as habilidades e competências, em termos de letramento, dos alunos, buscando descrever as estratégias de formação do hábito de leitura por parte dos educadores, a relação dos educandos com as bibliotecas disponíveis na região do Barreiro e o trabalho dos educadores no sentido de aproximá-los dessas bibliotecas. Analisei, também, a relação dos educandos e educadores com os recursos de multimídia disponíveis.

Nessa pesquisa, pude perceber a qualidade dos leitores que estão sendo formados, considerando que a leitura é um processo interativo em que o leitor é um agente que atua ativamente sobre o texto. Segundo Paulo Freire, a leitura da palavra é precedida pela leitura do mundo e é, também, uma forma de "escrevê-lo" ou de "reescrevê-lo" e de transformá-lo por meio da prática consciente do leitor. Portanto, a leitura, como definiu Magda Soares, não pode ser encarada como um processo de aquisição da "tecnologia da escrita" que se refere à alfabetização, mas está relacionada ao desenvolvimento de competências (habilidades, conhecimentos, atitudes) e ao uso efetivo dessa tecnologia em práticas sociais que envolvam a língua escrita. Essa idéia está relacionada, segundo Soares(1), ao letramento. A partir desses dados, busquei identificar as razões do baixo índice de leitura da população, a maneira como isso é tratado pelos educadores e educandos e de que forma os recursos de multimídia podem contribuir na formação de leitores. 


\section{Oportunidade de reflexão sobre o mundo}

Em uma entrevista a Roger Chatier, Jean Lebrum mostrou que, na Idade Média, era obrigatório o silêncio nas bibliotecas e que, no século XVIII, as sociedades de leitura na Europa rezavam, em seus regulamentos, que "o lugar de leitura [devia] ser separado dos lugares de um divertimento mais mundano"(2). Os leitores liam em um lugar retirado, privado, e o faziam sentados, com a coluna ereta. A partir do século XVIII, começou a ocorrer a dessacralização da leitura: há imagens desse período que "representam o leitor na natureza, o leitor que [lia] andando, que [lia] na cama". A partir daí, os leitores têm uma postura mais livre em relação ao livro.

Lebrum também afirma que, quando o jornal adquire um formato maior e uma distribuição mais ampla, ele proporciona uma atitude mais livre aos leitores, pois o mesmo pode ser carregado, rasgado, dobrado e lido por muitos.

Nota-se que com o passar dos séculos, os leitores se relacionam de forma mais livre ao ato de ler. Atualmente, há diversas formas de interação com a leitura: o texto não se encontra apenas no livro impresso, mas se apropria também dos recursos de multimídia, da fotografia e das diversas formas de manifestação da arte. A respeito disso, Lebrum afirma:

Se nos voltarmos para o artigo clássico de Walter Benjamim sobre a fotografia e o cinema, vemos que a fotografia e o cinema ligam-se ao homem comum e permitem uma abertura mais ampla para o mundo social. Assim, práticas não legítimas e mais espontâneas encontram-se representadas, enquanto antes elas não entravam nos códigos e temas da representação. (3)

Porém, mesmo havendo várias maneiras de se ler, cabe perguntar: o leitor tem habilidades e competências, em termos de letramento, para tal função? Ele é estimulado a ter prazer, por exercer tal função? Ou ele simplesmente lê por obrigação? Outras questões estão relacionadas ao acesso das pessoas aos suportes de leitura. Todos têm acesso, de maneira igual, aos suportes? Como estão distribuídos os espaços de leitura e as bibliotecas nas cidades? Qual é o preço dos livros em relação ao poder de aquisição dos leitores? A partir de minha observação das duas turmas acima citadas, tentei responder a essas questões.

Em nossa cultura, atribui-se à leitura um valor positivo absoluto: ela traria benefícios óbvios e indiscutíveis ao indivíduo e à sociedade, sendo uma forma de lazer e de prazer, de aquisição de conhecimento e cultura, de ampliação das condições de convívio e interação social. Contudo, analisei 
empiricamente a relação dos alunos com a leitura, observando se realmente eles atribuem esse valor e importância à mesma.

A primeira turma que analisei foi a da oficina de Letramento e Inclusão Digital desenvolvida pelo Programa de Ensino, Pesquisa e Extensão A tela e o texto. Essa oficina atendeu a seus alunos, proporcionando-lhes acesso a diversas formas de suportes de leituras como o computador, a televisão e a música, dentre outros. Comecei a observar essa oficina em abril de 2006 e, aos poucos, fui auxiliando a monitora da mesma em atividades de preparação e execução das aulas. Nessa turma, todos já sabiam ler. Então, a proposta era intensificar o nível de letramento de seus participantes.

Os encontros foram feitos uma vez por semana com a duração de três horas. A turma não era totalmente fixa. Alguns participantes foram a todas as aulas, mas a maioria freqüentou-as esporadicamente. Dentro do curso, houve uma livre circulação dos participantes: só permanecia no mesmo quem estivesse interessado: não havia nenhuma pressão por parte da monitora para que os mesmos permanecessem nas aulas. Também não havia um cronograma de aulas preestabelecido: a monitora preparava suas intervenções conforme o interesse dos participantes. Ela perguntava aos mesmos qual era o tema de seu interesse e, com base neles, preparava os encontros, proporcionando o letramento por meio da realidade de cada um. Essa atitude está relacionada com o discurso de Paulo Freire(4) sobre a alfabetização, mas suas idéias podem se estender também ao letramento, pois o autor defende a concepção de alfabetização como meio de democratização da cultura, como oportunidade de reflexão sobre o mundo.

Percebeu-se, então, que houve participação efetiva dos alunos nas atividades propostas, pois o tema abordado fazia parte da realidade deles. No encerramento do semestre, foi feita uma avaliação oral dos participantes em relação à oficina. A professora perguntou para eles qual fora o dia ou o tema de que eles mais gostaram durante o semestre. Cada um escolheu seu tema preferido, mas o motivo sempre foi o mesmo: eles relataram que gostaram do tema com que mais se identificavam. Por exemplo, um aluno disse que gostou do dia em que foi discutido futebol, pois ele pratica o esporte e acompanha os jogos pela televisão.

Os participantes dessa oficina não tinham contato com livros, ou seja, não tinham o hábito de ler. Em um dos encontros, a monitora levou para os participantes o livro o matador, de Patrícia Mello, no qual é narrada a vida de um jovem da periferia da cidade grande que se transforma em um matador de aluguel. Eles leram um trecho do livro, escolhido pela monitora, a qual, em seguida, exibiu uma cena do filme o homem 
do ano, de José Henrique Fonseca, que foi produzido com base no livro de Patrícia Mello. O trecho e a cena eram correspondentes e os participantes perceberam que havia algumas diferenças: no livro, era necessário ter uma descrição bem maior para se construir a cena do que no vídeo. Também no livro, aconteciam mais fatos em relação ao filme, o qual era mais sucinto. Um participante alegou que, quando leu o texto, imaginou as cenas de forma diferente das que foram retratadas no filme.

Durante esse processo de discussão, um participante em particular me chamou a atenção porque durante todo o encontro ele ficou com o livro nas mãos, folheando-o e lendo alguns trechos. Percebi que ele se interessou muito pelo livro, creio que seja pelo fato de abordar um tema que faz parte de sua realidade, por ter visto a cena do filme na televisão, que é o meio ao qual eles mais têm acesso, e pelo fato de a monitora não ter contado o final da narrativa, o que the provocou curiosidade e inquietação. Percebe-se que o maior problema desses participantes é a falta de acesso ao livro e de pessoas que os provoquem para esse ato, pois eles possuem habilidades e competências para ler, interpretar e discutir diversos textos.

A outra turma observada foi a da Educação de Jovens e Adultos (EJA), a partir do projeto de Educação de Trabalhadores. Os professores constroem os seus trabalhos antes, durante e depois da sala de aula, lugar no qual muitas vezes, há mais de um professor. Os docentes não trabalham nas áreas específicas em que se formaram na Graduação, já que o projeto se esforça para superar uma visão fragmentada de conhecimento. O projeto é estruturado para funcionar em um único ciclo, sem seriação, e todas as etapas do trabalho - a elaboração, a prática e a avaliação das atividades -, são realizadas, em conjunto, pelos professores que trabalham em diferentes áreas do conhecimento a partir da abordagem de temas das Ciências Físicas, Biológicas, Filosofia, Sociologia, Economia etc.

Há casos em que os alunos dão contribuições sobre o que estudar, em outros momentos, os professores definem os temas. Nesse projeto não há atribuições de notas, nem se trabalha com turmas fixas. Na prática, contudo, são criados os agrupamentos, os quais têm um tempo delimitado: eles começam os trabalhos juntos e se organizam para encerrarem juntos suas atividades. Nos dias da minha observação, contudo, eles estavam distribuídos em dois agrupamentos: Saberes e Identidade.

Percebi que a maioria dos alunos não tinha o hábito da leitura. Os professores trabalharam com eles utilizando textos acadêmicos. O tema escolhido foi o mito e a ciência em textos 
de Marilena Chauí e Rubem Alves. Antes de os textos serem lidos, os professores discutiram com os alunos o tema com o auxílio de filmes. Como os textos são de filosofia, foi necessária uma preparação para que fossem compreendidos. Depois dessas atividades, os textos foram lidos em sala de aula pelos alunos e discutidos juntamente com os professores, utilizando exemplos do dia-a-dia. Assim, a maioria deles participou ativamente das discussões, apesar de alguns ficarem um pouco confusos quando se depararam com conceitos que são abordados na Física e na Biologia. Mas essas dúvidas eram sanadas pelos educadores.

Percebe-se que essa é uma forma diferenciada de transmitir o conhecimento. Os alunos não adquiriram o conteúdo de uma forma passiva, eles participaram ativamente na sala de aula. Por exemplo, em uma aula, surgiu, a partir de um dos textos, uma dúvida em relação ao conteúdo de Geografia: a forma como os planetas, a lua e o sol se posicionam no espaço. A professora levou para a sala uma maquete que representava o sistema solar. Outro professor levou um livro, o qual estava disponível na biblioteca da escola, que contava a história dos mitos com ilustrações belíssimas. Com essa atitude, ele despertou o interesse e a curiosidade dos alunos para pegar o livro emprestado, posteriormente.

Nessas atividades, os alunos se sentiram estimulados a participar das aulas e a transmitir informações que eles já tinham a respeito do assunto. Para que atividades desse tipo se realizassem com sucesso, seria necessário que os educadores envolvidos nas mesmas tivessem uma boa formação. O trecho abaixo, retirado da revista Presença pedagógica(5), aborda essa necessidade:

É necessário que o professor passe por uma experiência socializadora de saberes, a qual lhe deve estar acessível; por outro lado, o professor deve reconstituir individualmente o que é de domínio da sociedade. Dessa forma, é o professor-sujeito da produção de significados sociais que estaremos formando, aquele que pode compreender e reelaborar os processos e as razões das interlocuções. Vale recuperar a noção de letramento, tão cara nas discussões sobre processos de aquisição da língua escrita por crianças e por jovens e adultos que retomam os bancos escolares, para sugerir a necessidade de o professor também estar, ele próprio, em contínuo processo de letramento, seja verbal, visual, verbovisual.

Observa-se, portanto, que não se deve ter a atenção voltada somente para os educandos, mas também para os educadores, os quais são peças fundamentais para que o processo de aprendizagem e o interesse pela leitura sejam despertados. O educador tem que estar atualizado não somente em termos de teoria da educação, mas também se informar sobre os interesses dos educandos. Ele precisa saber $O$ que eles estão lendo, 
assistindo na televisão ou acessando na Internet. Dessa forma, ocorrerá uma aproximação maior com os alunos no processo de aprendizagem.

Foram fornecidos, pela Prefeitura, materiais didáticos feitos especialmente para jovens e adultos. Porém, os mesmos não acompanham os objetivos do projeto. Os livros são divididos por matérias e a linguagem utilizada é semelhante aos livros de alfabetização infantil; a explicação dos conteúdos é cheia de metáforas, portanto, não aborda o assunto de forma objetiva e clara. A partir daí, percebe-se a impossibilidade de se trabalhar com esse material. Magda Soares(6) faz uma observação em relação à alfabetização que pode ser estendida ao letramento:

\begin{abstract}
A tecnologia da escrita é aprendida não como em concepções anteriores, com textos construídos artificialmente para a aquisição das "técnicas" de leitura e de escrita, mas através de atividades de letramento, isto é, de leitura e produção de textos reais, de práticas sociais de leitura e de escrita.
\end{abstract}

Portanto, a proposta enviada pela prefeitura, em termos da linguagem utilizada, não condizia com a realidade dos educandos. A partir desse fato, os professores optaram por não utilizar esse material, pois o mesmo não estabelecia um diálogo efetivo com os alunos. Busquei identificar também se os educandos em ambas as turmas tinham acesso à biblioteca. Verifiquei que os alunos da oficina não tinham acesso a esse equipamento cultural, apesar de nesse espaço haver uma sala de leitura. Contudo, ela se encontrava, à época, fechada, mesmo sendo uma biblioteca formada a partir do projeto Bibliotecas comunitárias do Programa de Ensino, Pesquisa e Extensão A tela e o texto que mobilizou os agentes culturais da região para a organização inicial do projeto. Também as turmas do EJA tinham acesso restrito à biblioteca, pois no turno da noite a bibliotecária responsável estava de licença, sem substituta.

Em ambas as turmas, foram utilizados recursos de multimídia. $\mathrm{Na}$ turma do EJA, os professores passaram filmes para auxiliar nas discussões dos temas e utilizaram a Internet para que os alunos fizessem pesquisas a fim de aprofundarem o conhecimento sobre o assunto trabalhado. $\mathrm{Na}$ oficina de letramento digital, - vídeo foi utilizado e a monitora exibiu filmes produzidos a partir de livros. Assim, eram feitas comparações entre os dois suportes. Os participantes dessa oficina, no início, não tinham acesso à Internet, mas desenvolveram atividades no programa Editor de Textos, escrevendo e se expressando melhor no computador. Mais tarde, foi instalada a Internet $e$, a princípio, houve dificuldade de compreensão da mesma por parte dos educandos. Para que os participantes compreendessem os recursos básicos da Internet, a monitora trabalhou com a música de Gilberto Gil cujo tema é a Internet, na qual há 
vários termos que são utilizados na linguagem da web. Os participantes fizeram um dicionário de Internet, selecionaram todas as palavras que se relacionam à mesma e, juntamente com a monitora, explicaram o significado e a função de cada uma. Após essa atividade, os participantes acessaram a Internet e se sentiram mais familiarizados com a mesma. Segundo Beiguelman(7), a Internet propicia

\begin{abstract}
um texto que agora se dá a ler em um meio que é também o meio que se escreve e, muitas vezes, no qual também se publica, agenciando um processo de reciclagem do conhecimento em uma escala sem precedentes, confundindo as práticas da escritura e da leitura. Um texto que se transmite em um fluxo de dados contínuo e que demanda pensarem um contexto de leitura líquida que não responde ao desenho retangular da janela do monitor nem ao enquadramento da página. Redefinem-se não só as experiências de leitura, porque se tornam agora relativas às diferenças entre texto, imagem e lugar, muito embora a metáfora da tela com a página mascare essa situação inédita.
\end{abstract}

Portanto, percebe-se que, para esses participantes que não tiveram um contato maior com o computador, torna-se difícil aceitar e assimilar todas as novidades que esse suporte traz. Nota-se que é necessário fazer essa transição, do papel para a tela, gradualmente, pois se for feita de forma brusca, os participantes podem ficar confusos.

\title{
A leitura e o aluno
}

A partir da observação das duas turmas e com o auxílio de uma bibliografia específica, nota-se que os alunos têm habilidades e competências para compreender, interpretar e discutir um texto a partir do ato da leitura. Porém, a forma como essa interação com o texto é trabalhada influencia na qualidade de sua produção. Notei que o educador é extremamente importante para o aprendizado e para a formação do hábito de leitura do aluno pois, se ele os estimular, eles produzirão com qualidade. Percebi que esse estímulo está relacionado com a maneira como o professor aborda o conteúdo a ser passado: ele deve considerar, primeiramente, a experiência do aluno e, a partir dela, construir o conhecimento.

Os recursos de multimídia auxiliaram essa aproximação do professor com os alunos. A televisão, a música e o computador foram utilizados para estimularem 0 interesse dos mesmos na leitura de textos literários. É importante que as atividades sejam preparadas a partir de temas, os quais se aproximem da realidade dos educandos, pois, assim, eles se sentirão confortáveis na sala de aula e produzirão adequadamente.

Percebi, ao final, que os alunos foram estimulados pelos educadores a obterem hábitos de leitura, porém, eles não tiveram acesso aos espaços de leitura. A sala de leitura 
disponível para a oficina de letramento digital se encontrava sempre fechada. E para a turma do EJA, a biblioteca não funcionava regularmente à noite (funcionava somente no período diurno). Como a maioria dos alunos trabalhava em horário integral, eles não tinham disponibilidade para utilizar a mesma. Essa situação impediu que fossem desenvolvidas melhores relações de cada aluno com romances, poesias, textos científicos, tecnológicos, jornalísticos e filosóficos. Em ambas as turmas, o processo de letramento, sem dúvida, ficou prejudicado.

\section{Resumen}

Este trabajo tiene por objetivo observar y analizar las estrategias de formación del hábito de lectura de los participantes de los talleres de letramento e inclusión digital realizados, respectivamente, por el Programa de Enseñanza, Investigación y Extensión A tela e o texto (FALE/UFMG) y por el Programa de Educación de Jóvenes y Adultos (EJA), en Belo Horizonte. A partir de la observación de los talleres y del análisis de los datos a la luz de la bibliografia específica, se verificó que la formación de lectores no contempla satisfactoriamente el uso de bibliotecas de la región y explota los recursos de multimedias (televisión, vídeo y ordenador), lo que denota, en la actualidad, un profundo cambio en la recepción de textos literarios.

Palabras clave: formación de lectores, mídia, recepción de textos.

\section{Notas}

(1) SOARES, 2003

(2) CHARTIER, 1999.

(3) CHARTIER, 1999.

(4) FREIRE, 1996.

(5) PRESENÇA PEDAGÓGICA, 2001.

(6) SOARES, 2003.

(7) BEIGUELMAN, 2003.

\section{Bibliografia}

ARAÚJo, Ricardo. Poesia visual. São Paulo: Perspectiva, 1999.

AUMONT, Jacques. A imagem. São Paulo: Papirus, 1995.

AUTHIER, Michel, LÉVY, Pierre. As árvores de conhecimentos. Trad. de Mônica 
M. Seincman. São Paulo: Escuta 1995.

CAMPOS, Haroldo de. A arte no horizonte do provável. São Paulo: Perspectiva, 1977 .

KLEIMAN, Ângela. Leitura: ensino e pesquisa. Campinas, SP: pontes, 1989. LÉVY, Pierre. A ideografia dinâmica: rumo a uma imaginação artificial? São Paulo: Loyola, 1998 .

LÉVY, Pierre. A inteligência coletiva: por uma antropologia do ciberespaço. Trad. De Luiz P. Rouanet. São Paulo: Loyola, 1998.

LÉVY, Pierre. As tecnologias da inteligência: o futuro do pensamento na era da informática. Trad. De Carlos I. da Costa. Rio de Janeiro: Editora 34, 1993.

LÉVY, Pierre. Cibercultura. Trad. De Carlos I. da Costa. Rio de Janeiro: Editora 34, 1999 .

LÉVY, Pierre. O que é o virtual? Trad. de Paulo Neves. Rio de Janeiro: Editora 34, 1996.

LIMA, Fernando Barbosa, PRIOLLI, Gabriel, MACHADO, Arlindo. Televisão e vídeo. Rio de Janeiro: Jorge Zahar, 1985.

MACHADO, Arlindo. A arte do vídeo. São Paulo: Editora Brasiliense, 1988. MACHADO, Arlindo. Máquina e imaginário. São Paulo: Editora da Universidade de São Paulo, 1996.

MACHADO, Arlindo. O vídeo e sua linguagem. Revista USP - Dossiê Cinema Brasil. São Paulo, n.16, Dez/Fev. 1992/1993.

MACHADO, Arlindo. O quarto iconoclasmo. Rio de Janeiro: Editora Rios Ambiciosos, 2001.

Revista PRESENÇA PEDAGÓGICA - Linguagens. Belo Horizonte, v.7, n.40, Jul./Ago.Ed. Dimensão, 2001.

SANTAELlA, Lúcia. Palavra, imagem e imagens. Revista USP - Dossiê Cinema Brasil. São Paulo, n.16, Dez/Fev. 1992/1993.

SOARES, Magda. Letramento no Brasil - Reflexões a partir do INAF 2001. São Paulo: Global, 2003.

SOARES, Magda. Letramento - um tema em três gêneros. Belo Horizonte: Autêntica, 2003.

VARGAS, Suzana. Leitura: uma aprendizagem de prazer. 3 ed.Rio de Janeiro:José Olimpio, 1997.

YUNES, Eliana. Pensar a leitura: complexidade. Rio de Janeiro: Ed. PUC-RIO: São Paulo: Loyola, 2002 .

WENDERS, Wim. A lógica das imagens. Rio de Janeiro: Edições 70, 1990. 